\title{
Placenta previa as a risk factor for antenatal- and peripartum periventricular leukomalacia resulting in cerebral palsy in
} Japan: a retrospective study [version 1; peer review: 1

\section{approved with reservations]}

\section{Shunji Suzuki (iD)}

Department of Obstetrics and Gynecology, Japanese Red Cross Katsushika Maternity Hospital, Katsushika-ku, Tokyo, 124-0012, Japan

V1 First published: 07 Apr 2020, 9:241

https://doi.org/10.12688/f1000research.22878.1

Second version: 06 May 2020, 9:241

https://doi.org/10.12688/f1000research.22878.2

Third version: 25 Aug 2020, 9:241

https://doi.org/10.12688/f1000research.22878.3

Latest published: 04 Nov 2022, 9:241

https://doi.org/10.12688/f1000research.22878.4

\section{Abstract}

Intrapartum fetal heart rate monitoring abnormalities had been reported to correlate with decreased umbilical artery base excess associated with neonatal seizures. After encountering a child born at 35 weeks of gestation diagnosed with cerebral palsy associated with periventricular leukomalacia (PVL) without fetal heart rate monitoring abnormalities, a review and analysis of summary reports of PVL cases published on the home page of the Japan Obstetric Compensation System for Cerebral Palsy (JOCSC). Based on the case and the review of the reports of PVL cases from JOCSC, placenta previa may be a risk factor for antenatal- and peripartum PVL resulted in cerebral palsy in Japan.

Keywords

periventricular leukomalacia, placenta previa, Japan

\begin{tabular}{l} 
Open Peer Review \\
Approval Status ? \\
version 4 \\
(revision) \\
04 Nov 2022 \\
version 3 \\
(revision) \\
25 Aug 2020 \\
version 2 \\
(revision) \\
06 May 2020 \\
$\begin{array}{l}\text { version 1 } \\
07 \text { Apr 2020 }\end{array}$ \\
\hline
\end{tabular}

1. Ambrogio Pietro Londero, University of Udine, Udine, Italy

2. Euiseok Jung $[\mathrm{D}$, University of Ulsan, Seoul,

South Korea

Any reports and responses or comments on the article can be found at the end of the article. 
Corresponding author: Shunji Suzuki (czg83542@mopera.ne.jp)

Author roles: Suzuki S: Conceptualization, Data Curation, Formal Analysis, Funding Acquisition, Investigation, Methodology, Project Administration, Resources, Software, Supervision, Validation, Visualization, Writing - Original Draft Preparation, Writing - Review \& Editing

Competing interests: No competing interests were disclosed.

Grant information: The author(s) declared that no grants were involved in supporting this work.

Copyright: ๑ 2020 Suzuki S. This is an open access article distributed under the terms of the Creative Commons Attribution License, which permits unrestricted use, distribution, and reproduction in any medium, provided the original work is properly cited.

How to cite this article: Suzuki S. Placenta previa as a risk factor for antenatal- and peripartum periventricular leukomalacia resulting in cerebral palsy in Japan: a retrospective study [version 1; peer review: 1 approved with reservations] F1000Research 2020, 9:241 https://doi.org/10.12688/f1000research.22878.1

First published: 07 Apr 2020, 9:241 https://doi.org/10.12688/f1000research.22878.1 


\section{Introduction}

Brain injury in premature infants is generally thought to primarily consist of periventricular leukomalacia (PVL), a distinctive form of cerebral white matter injury. PVL occurs most commonly in premature infants born at less than 32 weeks' gestation. In an earlier study in Japan, frequent moderate variable deceleration on fetal cardiotocogram (CTG) was observed to be a cause of antenatal PVL in premature infants ${ }^{1}$. In the report by Ito et al. ${ }^{1}$, frequent moderate variable decelerations on fetal CTG were observed frequently for infants with antenatal PVL $(80.0 \%)$ than control infants $(27.3 \%, p<0.05)$. In addition, in low birth weight infants, intrapartum severe variable deceleration or prolonged deceleration have been suggested to play a causal role in $\mathrm{PVL}^{2}$. Although intrapartum fetal heart rate monitoring abnormalities had been reported to correlate with decreased umbilical artery base excess associated with neonatal seizures, recently it has been observed to have no relation to perinatal mortality or pediatric neurologic morbidity ${ }^{3,4}$. The main factor related to the presence of PVL has been suggested to be gestational age ${ }^{4}$.

We encountered a case of PVL without fetal heart rate monitoring abnormalities. Subsequently, a review and analysis of the summary reports of PVL cases published on the home page (HP) of the Japan Obstetric Compensation System for Cerebral Palsy (JOCSC) was conducted. We conclude that placenta previa may be a risk factor for antenatal- and peripartum PVL resulting in cerebral palsy $(\mathrm{CP})$ in Japan.

\section{Case report}

An elective cesarean section was performed at 35 weeks' gestation because of placenta previa in the mother with warning bleeding of $60 \mathrm{~g}$. A 2346-g, male infant was delivered with Apgar scores of 8 and 9 at 1 and 5 minutes, respectively. The mother's pregnancy had progressed uneventfully until the day before the cesarean section. The preoperative fetal CTG, performed 20 minutes before the cesarean section, showed a reassuring fetal status without any fetal heart rate decelerations. The umbilical artery $\mathrm{pH}$ was 7.334. The total blood loss during cesarean section was $1,080 \mathrm{~g}$. The infant had no problems during his neonatal period; however, he was diagnosed with $\mathrm{CP}$ associated with PVL at the age of 2 .

\section{Review and analysis of PVL cases on JOCSC}

To re-examine previous findings in Japan regarding PVL cases, we reviewed the summary reports of antenatal- and peripartum PVL cases published on the HP of the JOCSC launched in $2009^{5}$. This is a free to access resource, and the cause analysis reports (summary reports) of the patients can be accessed here: http://www.sanka-hp.jcqhc.or.jp/documents/ analysis/index.html. Those eligible for inclusion in the compensation scheme are infants born between 2009 and 2014 with a birth weight of $\geq 2,000 \mathrm{~g}$, gestation of $\geq 33$ weeks and infants born between 2015 and 2019 with a birth weight of $\geq 1,400$ $\mathrm{g}$, gestation of $\geq 32$ weeks, and severe disability due to $\mathrm{CP}$ independent of congenital causes or factors during the neonatal period or later. In the current study, we searched all summary reports published by the end of March 2020 using the keyword 'PVL'. We have excluded the cases of PVL identified as neonatal cause, such as late circulatory collapse, birth injury, and multiple pregnancies, from the analysis. The following variables were extracted from the reports: fetal heart rate decelerations, intrauterine infection, placental abruption and placenta previa.

Data are presented as number (\%). SPSS Statistics software version 20 (IBM Csorp., Armonk, NY, USA) was used for statistical analyses. For statistical analysis, the $\mathrm{X}^{2}$ test was used for the categorical variables between cases with and without fetal heart rate decelerations. Differences with $p<0.05$ were considered significant.

\section{Findings}

There were 209 cases of PVL published in the HP of JOCSC retrieved in January 2020. We examined the presence or absence of moderate/severe decelerations (MSDs) on fetal CTG in 187 cases. Cases excluded were 13 cases of monochorionic twins and 9 cases of postnatal PVL due to late circulatory collapse $(\mathrm{n}=6)$, neonatal hypoglycemia $(\mathrm{n}=2)$ and neonatal hyperkalemia $(n=1)$. Table 1 shows the clinical characteristics of the 187 cases of antenatal- and peripartum PVL with and without MSDs on fetal CTG. The incidence of neonatal asphyxia in the cases with MSDs was higher than in those without MSDs $(p<0.01)$; however, the percentage of cases without MSDs was higher than those with MSDs (73.3 vs. $26.7 \%$, $p<0.01)$. In cases without MSDs, the percentage of neonates born at term was higher than those with MSDs $(p=0.04)$. These cases might have potentially transient episodes leading to PVL in the uterus between 26 and 32 weeks of gestation. Our case may be same as these cases.

Table 2 shows the perinatal complications in the cases of antenatal- and peripartum PVL with and without MSDs on fetal CTG. The incidence of intrauterine infection and placental abruption in the cases with MSDs was higher than those without MSDs $(p<0.01)$, while the incidence of placenta previa in the cases without MSDs was higher than those with MSDs $(p=0.04)$. The former results were as expected, while the latter may be a new finding. The percentage of placenta previa in the cases of PVL was 5.7\% (12/209), which seemed to be higher than the total percentage of placenta previa reported in Japan $(0.3-0.5 \%)^{6}$.

\section{Discussion}

To date, some possible mechanisms leading to PVL in cases of placenta previa has been discussed in $\operatorname{Japan}^{7,8}$. Oda et al. ${ }^{7}$ reported that the main risk factor for PVL in preterm placenta previa is an initial antepartum hemorrhage $<28$ weeks of gestation and they speculated that decreased placental perfusion in the second trimester of pregnancy is associated with the developmental window of vulnerability for PVL. However, Furuta et al. ${ }^{8}$ observed that acute and massive bleeding from placenta previa at around 30 weeks of gestation is a risk factor for PVL and CP requiring careful neonatal follow-up. 


\begin{abstract}
Table 1. Clinical characteristics of antenatal- and peripartum periventricular leukomalacia with and without moderate/severe decelerations on fetal cardiotocogram.
\end{abstract}

\begin{tabular}{|c|c|c|c|c|c|}
\hline & \multicolumn{2}{|c|}{$\begin{array}{c}\text { Moderate/severe } \\
\text { decelerations, } n(\%)\end{array}$} & \multirow[t]{2}{*}{$P$-value } & \multirow[t]{2}{*}{ Odds ratio } & \multirow[t]{2}{*}{$\begin{array}{c}95 \% \text { Confidence } \\
\text { Interval }\end{array}$} \\
\hline & $(+)$ & $(-)$ & & & \\
\hline Total & 50 & 137 & & & \\
\hline \multicolumn{6}{|c|}{ Gestational age at delivery (weeks) } \\
\hline$<30$ & $12(24.0)$ & $29(21.2)$ & 0.15 & 0.471 & $0.18-1.2$ \\
\hline $30-31$ & $14(28.0)$ & $26(19.0)$ & 0.22 & 0.512 & $0.19-1.4$ \\
\hline $32-33$ & $15(30.0)$ & $33(24.1)$ & 0.46 & 0.607 & $0.23-1.6$ \\
\hline $34-36$ & $8(16.0)$ & $29(21.2)$ & Ref. & 1 & - \\
\hline$\geq 37$ & $0(0)$ & $20(14.6)$ & 0.04 & Inf. & 1.3-Inf. \\
\hline \multicolumn{6}{|c|}{ Cesarean delivery } \\
\hline No & $21(42.0)$ & $52(38.0)$ & Ref. & 1 & - \\
\hline Yes & $29(58.0)$ & $85(62.0)$ & 0.62 & 1.19 & $0.62-2.3$ \\
\hline \multicolumn{6}{|c|}{ Apgar score at $1 \mathrm{~min}$} \\
\hline$<4$ & $22(44.0)$ & $27(19.7)$ & $<0.01$ & 0.223 & $0.098-0.51$ \\
\hline $4-6$ & $16(32.0)$ & $44(32.1)$ & 0.14 & 0.500 & $0.22-1.1$ \\
\hline$\geq 7$ & $12(24.0)$ & $66(48.2)$ & Ref. & 1 & - \\
\hline \multicolumn{6}{|c|}{ Urinalysis $\mathrm{pH}$} \\
\hline$\geq 7.0$ & $34(68.0)$ & $115(99.1)$ & Ref. & 1 & - \\
\hline$<7.0$ & $11(22.0)$ & $1(0.9)$ & $<0.01$ & 0.0270 & $0.004-0.17$ \\
\hline \multicolumn{6}{|c|}{ Fetal growth restriction } \\
\hline No & $41(82.0)$ & $117(85.4)$ & Ref. & 1 & - \\
\hline Yes & $9(18.0)$ & $20(14.6)$ & 0.65 & 0.779 & $0.33-1.8$ \\
\hline
\end{tabular}

\begin{abstract}
Table 2. Perinatal complications in the cases of antenatal- and peripartum periventricular leukomalacia with and without moderate/severe decelerations on fetal cardiotocogram.
\end{abstract}

\begin{tabular}{|c|c|c|c|c|c|}
\hline & \multicolumn{2}{|c|}{$\begin{array}{c}\text { Moderate/severe } \\
\text { decelerations, } n(\%)\end{array}$} & \multirow[t]{2}{*}{$P$-value } & \multirow[t]{2}{*}{ Odds ratio } & \multirow[t]{2}{*}{$\begin{array}{l}\text { 95\% Confidence } \\
\text { Interval }\end{array}$} \\
\hline & $(+)$ & $(-)$ & & & \\
\hline Total & 50 & 137 & & & \\
\hline \multicolumn{6}{|l|}{ Perinatal complications } \\
\hline Intrauterine infection & $19(38.0)$ & $22(16.1)$ & $<0.01$ & 0.312 & $0.15-0.64$ \\
\hline Placental abruption & $8(16.0)$ & $3(12.2)$ & $<0.01$ & 0.118 & $0.032-9.4$ \\
\hline Placenta previa & $0(0)$ & $12(8.8)$ & 0.04 & Inf. & 1.2-Inf. \\
\hline
\end{tabular}

However, in the 12 cases of placenta previa in that study, massive bleeding and initial bleeding $<28$ weeks of gestation were observed in only $4(33.3 \%)$ and 1 cases (8.3\%) Kmazaki et $a{ }^{9}{ }^{9}$ observed that gross lesions with disturbance of uteroplacental circulation including massive retroplacental hematoma, extensive infarction or thrombosis, and marked basal or perivillous fibrin deposition frequently in placentae in cases of antenatal- and peripartum PVL. They also observed the high frequency of ischemic changes in villi in those placentae. The same findings have been reported to be observed in cases of placenta previa ${ }^{10}$. The same findings may have occurred in our case. 
Based on the data from JOCSC, serious abnormal fetal heart rate patterns were not observed in approximately $70 \%$ of cases with antenatal- and peripartum PVL on fetal CTG, and placenta previa itself may be associated with the development of antenatal- and/or peripartum PVL.

\section{Data availability}

\section{Underlying data}

The Japan Obstetric Compensation System for Cerebral Palsy (JOCSC) for is a free to access resource. Cause analysis reports (summary reports) for patients with periventricular leukomalacia can be accessed here: http://www.sanka-hp.jcqhc. or.jp/documents/analysis/index.html, Feb 12, 2020). These reports are in Japanese.

Figshare: Data of PVL in Japan, https://doi.org/10.6084/ m9.figshare.12033501.v3 ${ }^{11}$.
This project contains the following underlying data:

Dataset 1. Raw data for gestational age, delivery mode, birth weight, Apgar scores, FHR deceleration, placenta abruption, complications, placenta previa from 187 the cases of periventricular leukomalacia on the home page of the Japan Obstetric Compensation System for Cerebral Palsy (JOCSC: http://www. sanka-hp.jcqhc.or.jp/documents/analysis/index.html, Feb 12, 2020).

Data are available under the terms of the Creative Commons Zero "No rights reserved" data waiver (CC0 1.0 Public domain dedication).

\section{Consent}

Written informed consent for publication of the clinical details of the case report was obtained from the mother in the case report.
1. Ito $\mathrm{T}$, Kadowaki $\mathrm{K}$, Takahashi $\mathrm{H}$, et al.: Clinical features of and cardiotocographic findings for premature infants with antenatal periventricular leukomalacia. Early Hum Dev. 1997; 47(2): 195-201. PubMed Abstract | Publisher Full Text

2. Ibara $\mathrm{S}$, Ikenoue $\mathrm{T}$, Sameshima $\mathrm{H}$, et al.: [The perinatal risk factors and periventricular leukomalacia (PVL) in premature infants--relationship between fetal heart rate decelerations and PVL]. No To Hattatsu. 1996; 28(2): 135-137. PubMed Abstract

3. Graham EM, Petersen SM, Christo DK, et al.: Intrapartum electronic fetal heart rate monitoring and the prevention of perinatal brain injury. Obstet Gynecol. 2006; 108(3 Pt 1): 656-666.

PubMed Abstract | Publisher Full Text

4. Romero-Guzman GJ, Lopez-Munoz F: [Prevalence and risk factors for periventricular leukomalacia in preterm infants. A systematic review]. Rev Neurol. 2017; 65(2): 57-62.

PubMed Abstract

5. Japan Council for Quality Health Care: The Japan Obstetric Compensation System for Cerebral Palsy. 2020.

Reference Source
6. Japan Society for Obstetrics and Gynecology: Placenta previa (in Japanese). 2020. Reference Source

7. Oda N, Takeuchi K, Tanaka A, et al: Obstetric risk factors associated with the development of periventricular leukomalacia in preterm infants born to mothers complicated by placenta previa. Fetal Diagn Ther. 2008; 24(4): 345-348. PubMed Abstract | Publisher Full Text

8. Furuta K, Tokunaga S, Furukawa $S$, et al:: Acute and massive bleeding from placenta previa and infants' brain damage. Early Hum Dev. 2014; 90(9): 455-458. PubMed Abstract | Publisher Full Text

9. Kumazaki K, Nakayama M, Sumida $\mathrm{Y}$, et al:: Placental features in preterm infants with periventricular leukomalacia. Pediatrics. 2002; 109(4): 650-655. PubMed Abstract | Publisher Full Text

10. Biswas R, Sawhney H, Dass R, et al.: Histopathological study of placental bed biopsy in placenta previa. Acta Obstet Gynecol Scand. 1999; 78(3): 173-179. PubMed Abstract | Publisher Full Text

11. Suzuki, Shunji: Data of PVL in Japan. figshare. Dataset. 2020. http://doi.org/10.6084/m9.figshare.12033501.v3 


\section{Open Peer Review}

\section{Current Peer Review Status: ?}

\section{Version 1}

Reviewer Report 27 April 2020

https://doi.org/10.5256/f1000research.25256.r62089

(C) 2020 Londero A. This is an open access peer review report distributed under the terms of the Creative Commons Attribution License, which permits unrestricted use, distribution, and reproduction in any medium, provided the original work is properly cited.

\section{Ambrogio Pietro Londero}

Clinic of Obstetrics and Gynecology, DAME, ASUI - Presidio Ospedaliero Universitario "SM della Misericordia", University of Udine, Udine, Italy

I read the article by Suzuki S entitled: "Placenta previa as a risk factor for antenatal- and peripartum periventricular leukomalacia resulting in cerebral palsy in Japan: a retrospective study" with interest.

The argument is very interesting but I have some points to highlight in order to improve the manuscript itself:

\section{Major issues:}

1. The abstract does not reflect in a proper manner the content of the manuscript. In particular, the conclusion in the abstract is a clear overstatement. In fact, the data analyzed in the manuscript do not allow any kind of conclusion about a correlation between placenta previa and neonatal periventricular leukomalacia. In the dataset, only cases of neonatal periventricular leukomalacia without controls are present.

2. For the same reason, the title of the article is also not appropriate, and also the manuscript's main-text itself should be fixed.

3. For the clinical case report, I suggest following the CARE guidelines.

\section{Minor issues:}

1. A minor issue is that the clarity of the whole manuscript would benefit from a revision of the English language.

Is the work clearly and accurately presented and does it cite the current literature? Partly

Is the study design appropriate and is the work technically sound? 
Partly

Are sufficient details of methods and analysis provided to allow replication by others? Yes

If applicable, is the statistical analysis and its interpretation appropriate? Partly

Are all the source data underlying the results available to ensure full reproducibility? Yes

Are the conclusions drawn adequately supported by the results? No

Competing Interests: No competing interests were disclosed.

I confirm that I have read this submission and believe that I have an appropriate level of expertise to confirm that it is of an acceptable scientific standard, however I have significant reservations, as outlined above.

Author Response 27 Apr 2020

Shunji Suzuki, Japanese Red Cross Katsushika Maternity Hospital, Katsushika-ku, Japan

Thank you very much for the comments and critique of my manuscript. I have been able to respond positively to each suggestion and we believe the paper has been strengthened. The changes are highlighted with red color.

I have re-written the abstract, case report and the title according to your suggestions. In addition, my English has been edited.

Thank you very much for your suggestions, again.

I do hope and trust that with these changes the manuscript is now acceptable for publication.

Thank you for considering my paper.

Sincerely yours,

Shunji Suzuki, MD

Department of Obstetrics and Gynecology,

Japanese Red Cross Katsushika Maternity Hospital

5-11-12-2 Tateishi, Katsushika-ku, Tokyo 124-0012 Japan

Tel: +81-3-3693-5211

Fax: +81-3-3694-8725 
e-mail: czg83542@mopera.ne.jp

Competing Interests: There are no competing interests.

\section{Author Response 30 Oct 2022}

Shunji Suzuki, Japanese Red Cross Katsushika Maternity Hospital, Katsushika-ku, Japan

Dear Professor Ambrogio Pietro Londero、

Thank you very much for your previous suggestions.

I have responded to your questions on May 2020.

If you have further suggestions.

Please guide me, again.

Sincerely,

Shunji Suzuki

Competing Interests: None.

The benefits of publishing with F1000Research:

- Your article is published within days, with no editorial bias

- You can publish traditional articles, null/negative results, case reports, data notes and more

- The peer review process is transparent and collaborative

- Your article is indexed in PubMed after passing peer review

- Dedicated customer support at every stage

For pre-submission enquiries, contact research@f1000.com 